\title{
Artificial Intelligence applied to the reduction of environmental impact in the construction of high- speed rail infrastructures
}

\author{
[ M. Parra, M. Galende, L. Pablos, A. Moral, J. Rodríguez, F. Campo, R. Carnerero, G.I. Sainz-Palmero, J.M. Benítez ]
}

\begin{abstract}
The development of a society is closely related to the quantity and quality of its infrastructures. Investment in infrastructures such as transport, energy, telecommunications are vital to the development of a country.
\end{abstract}

It is estimated that global demand for mobility and transport infrastructure for 2050 will be raised by $60 \%$ compared to 2010 data [1]. This means a very significant increase in the number of kilometers of roads and railways to build in the coming years.

The report "Green House Gases EU Transport Emissions: Routes to 2050" [2] indicated that $28 \%$ of total emissions associated with rail transport are due to infrastructure. Nearly half of these emissions are caused during the infrastructure construction process. Most of these emissions are mainly due to material production, transport and earthmoving. The construction of sustainable transport infrastructures is a growing priority in the policies of many countries around the world, including aspects such as social, environmental (related to climate change) and economic impact. Efficiency in the construction and management of transport infrastructure are key to sustainable development goals.

The transport infrastructure, such as high-speed rail lines poses a major effort in construction and even more, in terms of scheduling and resource management. Proper planning of tasks and resources in construction is essential to improve or optimize the environmental impact.

Under the framework of the European project LIFE12 ENV / ES / 000686, "LCA, environmental footprints and intelligent analysis for the rail infrastructure construction sector", a decision support tool has been developed for the implementation phase, which aims to reduce the water and carbon footprints by $5 \%$ and $10 \%$ respectively, by the application of artificial intelligence algorithms.

The tool is intended for agents involved in the construction of high-speed rail infrastructure. It allows to model the entire work, and, based on multi-objective evolutionary algorithms [3], to obtain a set of feasible solutions for scheduling tasks and resources. Each of these solutions is part of the Pareto front and quantifies compensations in the satisfaction of the different objectives, or the search for a unique solution that satisfies the subjective preferences of a human decision-making. The goal of this work is to provide a multi-objective evolutionary algorithm to optimize the decision-making process and analysis of building resource-constrained project scheduling for this kind of infrastructures, minimizing the environmental impact.

Keywords-intelligent analisys, carbon footprints, water footprints, high-speed train, jobs scheduling, multi-objective, environmental impact

M. Parra, José M. Benítez

University of Granada

Spain

M. Galende, L. Pablos, A. Moral, G.I. Sainz-Palmero

CARTIF

Spain

J. Rodríguez

VIAS Y CONSTRUCCIONES S.A.

Spain

F. Campo, R. Carnenero

IK Ingeniería

Spain 


\section{Acknowledgment}

This work has been partially supported by European Union LIFE+ financial instrument, under grant agreement no. LIFE12 ENV/ES/00068.

\section{References}

[1] Global land transport infraestructure requeriments. "Estimating road and railway infrastructure capacity and costs to 2050". International Energy Agency Available: https://www.iea.org/publications/freepublications/publication/TransportI nfrastructureInsights_FINAL_WEB.pdf. Last visited on 10th, Jul. 2017.

[2] EU Transport GHG: Routes to 2050. http://www.eutransportghg2050.eu/cms/. Last visited on 8th, Jul. 2017.

[3] Deb, K. "Multi-objective optimization using evolutionary algorithms". John Wiley \& Sons, 2001.

About Author (s):

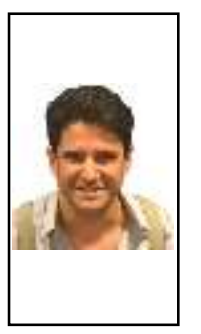

Manuel Parra is a $\mathrm{PhD}$. candidate at the department of Computer Science and Artificial Intelligence at University of Granada. MsC in Data Science and Intelligent systems. His research interests include machine learning, data mining and cloud computing.

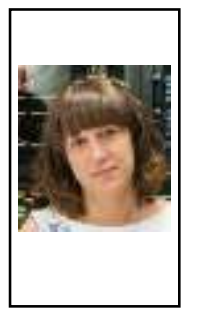

Marta Galende received his $\mathrm{PhD}$. in Computer Science Engineering in 2006 and MEng in 2008, both from the University of Valladolid (Spain). Fulltime researcher at Systems Division in Fundación CARTIF since 1999.

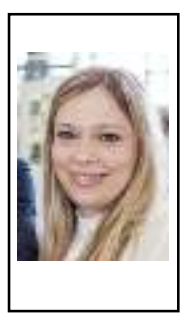

Laura Pablos is Chemical Engineer since 2008 and Master of Engineering since 2011, both from the University of Valladolid (Spain). Expert in assessing the environmental sustainability of different solutions via LCA studies

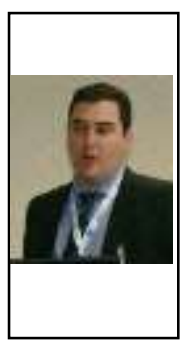

Jorge Rodríguez is graduated in Environmental Science at University of Córdoba and Senior Health and Safety Technician in Workplace Risk Prevention. Head of Environmental and ICT's Innovation Projects in VIAS y Construcciones.

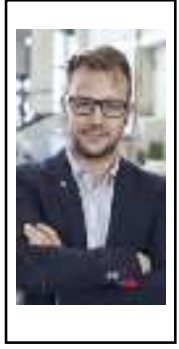

Alberto Moral is $\mathrm{PhD}$ in Environmental Engineering (University Alfonso X el Sabio) and $\mathrm{MsC}$ in Chemistry (University of Valladolid). Working in CARTIF since 2003, sector of Sustainability, using environmental tools as LCA, Ecodesign and Environmental Product Declarations.

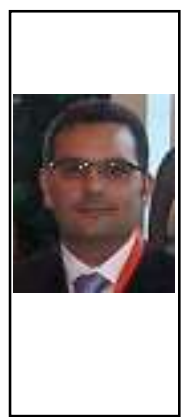

Rubén Carnerero is Industrial Engineer specialized in Manufacturing (University of the Basque Country). Co-Founder, Technical Director and Project Manager at IK Ingeniería since 2005. His main interests are Life Cycle Assessment, Environmental product Declaration, Ecodesign, Ecoinnovation, Supply Chain and Circular Economy.

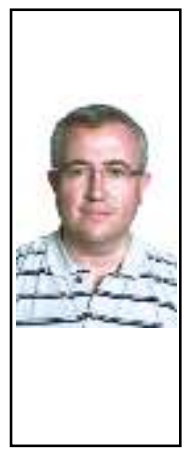

Gregorio Sainz-Palmero received the degree in Electrical Engineering in 1992 and a PhD. in Information Technologies in 1997, both from the University of Valladolid. He is an Associate Professor in the Department of System Engineering and Automatic Control at the University of Valladolid. His research interests include machine learning, fuzzy systems, industrial applications.

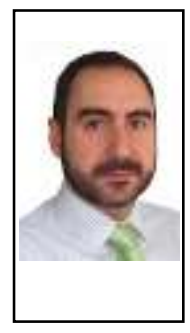

Francisco Campo is Industrial Engineer specialized in Mechanical Design (University of the Basque Country). Senior Health and Safety Technician in Workplace Risk Prevention. Co-Founder, Managing Director and Project Manager at IK Ingeniería since 2005.

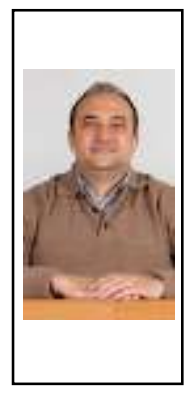

José M. Benítez received the M.S. and PhD. degrees in Computer Science both from the Universidad de Granada, Spain. $\mathrm{He}$ is currently an Associate Professor at the Department of Computer Science and Artificial Intelligence, Universidad de Granada. He is the head of the Distributed Computational Intelligence and Time Series. 